\title{
The community mathematics project: Using a parent tutoring program to develop sense-making skills in novice mathematics educators
}

\author{
Denisse M. Hinojosa ${ }^{1}$ D Emily P. Bonner ${ }^{1}$ (D)
}

Received: 25 May 2021 / Revised: 14 September 2021 / Accepted: 29 September 2021

(c) Mathematics Education Research Group of Australasia, Inc. 2021

\begin{abstract}
Programs that provide underserved populations with access to high-quality mathematics through workshops, clubs, and classroom observations (Civil, Stoehr, \& Salazar, 2019; Civil \& Bernier, 2006; Diaz-Palomar, Menendez, \& Civil, 2011; Jimenez-Castellanos, Ochoa, \& Olivos, 2016; Muir, 2011, 2012; Quintos, Civil, \& Bratton, 2019) are vital. The community mathematics project (CMP) is one such program that takes a holistic approach to transforming mathematics education. Through partnerships with local institutions, the CMP pairs a prospective teacher (PT) with a parent for online mathematics tutoring sessions. This study describes how PTs in the CMP supported parents' mathematics development of sense-making (Odden \& Russ, 2017) in mathematics by providing relevant tasks, employing multiple strategies, using virtual manipulatives, and questioning in one-one-one tutoring sessions. Findings suggest that this type of field experience with an explicit focus on a sense-making approach supported PTs in learning mathematics, engaging in partnerships with parents and members of the community, and attending broader issues of social contexts of learning. Further, PTs attended to individual considerations such as sequencing and scaffolding, relevancy of the content, task development, and building towards common mathematical practices. Finally, onsite coaching and tutoring experiences were formative in developing essential skills for teaching mathematics in elementary school in the following areas: content and pedagogical content knowledge, development of core pedagogical practices, funds of knowledge approaches and collaboration with families, and dispositions toward (teaching) mathematics such as reframing mistakes, emphasis on sense-making, and co-construction of knowledge.
\end{abstract}

Keywords Sense-making · Prospective teachers · Onsite coaching · Questioning · Virtual manipulatives

Denisse M. Hinojosa denisseh66@gmail.com

Extended author information available on the last page of the article 


\section{Introduction}

Mathematics teacher educators have a unique and vital opportunity to engage prospective teachers (PTs) in formative experiences that force interrogation of dominant narratives in traditional schooling spaces (Gutiérrez, 2018). Well-prepared mathematics teachers are not only knowledgeable in content and pedagogical skills that attend to issues of equity, but also in community resources and practices that can serve as foundations for accessible mathematical tasks (AMTE, 2017). These educators recognize relationships with caregivers, such as parents, as foundational to equitable practice (Aguirre et al., 2013; Author, 2012). This paper describes part of a large study that investigated outcomes related to the Community Math Project (CMP), a program that includes 1-1 tutoring sessions between a PT and a parent from a traditionally underserved community. The CMP includes tutoring in content and pedagogy, onsite coaching for PTs, community building activities between PTs and parents, and broader community events. While we collected and analyzed data related to the entire program, this manuscript will focus on PT learning and outcomes. Specifically, we describe how PTs in the CMP supported parents' mathematics sense-making by providing multiple strategies using virtual manipulatives and questioning to solve word problems in one-on-one tutoring sessions.

\section{Literature review}

The education reform (NCTM, 2000) shifted the way teacher preparation programs viewed mathematics methods courses and field experiences (Swars \& Hart, 2009) pushing mathematics educators to require mathematical content knowledge for teaching (Ball et al., 2008), provide strategies to support diverse learners, focus on understanding the context of problem-solving, and have in place systematic and connected clinical experiences (Darling-Hammond et al., 2002). This presented challenges for teacher preparation programs as they had to prepare PTs toward developing in-depth understanding of meanings associated with mathematics content and pedagogy to support students' mathematical reasoning through problem-solving. This means that teacher preparation programs can benefit from considering the ideas from the education reform to shape teaching based on how people learn and what they need to learn (Cochran-Smith \& Villegas, 2015). Further, teacher preparation programs can provide spaces for PTs to enact the content of university coursework while developing their teaching practice (Swars \& Hart, 2009).

\section{Connecting theory and practice in mathematics teacher learning}

Since the 1900s, continuous efforts have been made to promote PTs to make connections to methods and foundational courses in their field experiences with the goal of bridging the gap between theory and practice (i.e., Berliner, 1985; Darling-Hammond, 2006; Fraser, 2007; Grossman, 2005; Grossman et al., 2009; 
Zeichner, 2010). Field experiences are powerful components in teacher preparation programs because they support PTs in developing skills to facilitate learning sessions (Arbaugh et al., 2015; Henry et al., 2013; Wilson et al., 2001).

Research suggests that in most cases, field experiences are limited and disconnected from university coursework making it challenging for PTs to enact what they learned in university coursework (Wilson et al., 2001). Another reason is the ways in which apprenticeship of observation (Lortie, 1975) can influence the ways in which PTs view mathematics teaching (Swars \& Hart, 2009). For instance, PTs can be overwhelmed and revert to the ways their mentor or cooperating teachers teach at schools, leaving aside what PTs learned in teacher preparation programs (Wilson et al., 2001).

Another reason for the disconnect between university-based teacher preparation and teaching practices is part due to not focusing on student learning (Cochran-Smith \& Villegas, 2015). Making connections between teacher and student learning can provide alternative ways to think about teacher and student success, equity, and access (Cochran-Smith \& Villegas, 2015; Diez, 2010; Wilson et al., 2001). To make these connections, PTs can receive onsite coaching supports while developing their teaching practice to have a better understanding on how people learn considering knowledge and skills that people in the twenty-first century need. For example, provide PTs with opportunities to facilitate how to solve mathematical problems, provide spaces for learners to discuss their mathematical thinking, and use of problem-solving strategies (Swars \& Hart, 2009). Further, prepare PTs to allow learners construct knowledge, use learners' prior knowledge as basis for subsequent instruction, and facilitate mathematics around understanding and problem-solving (Carpenter et al., 1999, 2003).

\section{Digital technologies in mathematics education}

Digital technologies are embedded in teaching and influence teachers' work (AdamsBecker et al., 2017). PTs benefit from learning pedagogical approaches to develop digital competencies that give PTs the confidence to integrate digital tools in their teaching (Cochran-Smith \& Villegas, 2015; Darling-Hammond, 2012; Kaufman, 2015). Being digitally competent means that PTs are capable to use problem strategies, negotiate, and integrate digital technologies to promote student learning.

Since the year 2000 (ISTE, 2000; NCTM, 2000), there has been a push for teacher preparation programs to prepare PTs to be computer literate to support students improve mathematics achievement. That is, prepare PTs so that they are confident on choosing and incorporating the right technology tools as they develop their teaching practice. Studies suggest that incorporating technology in mathematics instruction promotes students' achievement, self-concept, higher-order thinking skills, teacher-student interaction, and so on (Kerrigan, 2002; Mistretta, 2005; Wright, 1999). Thus, Darling-Hammond et al. (2002) shared that in a study with 2956 novice teachers reported to feel ill-prepared on the use of technology. 


\section{Sense-making and virtual manipulatives to teach mathematics}

The National Council of Supervisors of Mathematics (NCSM, 2013) encourages the use of manipulatives, virtual manipulatives, and concrete representations to support students make sense of mathematics prior to learning abstract mathematics. Virtual manipulatives are visual representations of manipulatives (e.g., base-ten-blocks, two-color counters, Cuisenaire rods) used in virtual spaces to promote sense-making and support logical reasoning prior using abstractions. The use of virtual manipulatives supports learners to externalize mathematics representations and promotes learning by allowing students to reflect on mathematics properties (Beck \& Huse, 2007; Moyer \& Suh, 2012; Moyer-Packenham \& Westenskow, 2013; Zbiek et al., 2007).

Sense-making is a dynamic process that allows participants to resolve absent knowledge through the co-construction of knowledge and building from prior knowledge (Odden \& Russ, 2017). Learners are able to make sense of mathematics when they use concrete mathematics from daily experiences and connect those to abstract mathematics (Hammer \& Zee, 2006; Knijnik, 2003; Plaza et al., 2004). Approaches used in school settings follow the NCSM guidance. Therefore, for PTs to support parents in tutoring sessions, and to use sense-making in their field experiences, PTs need to be familiar with these new mathematics approaches (Ginsburg, 2006; Remillard \& Jackson, 2006).

\section{Community mathematics project}

The CMP is an initiative designed to transform mathematics education outside the traditional structure of schools to empower traditionally underserved communities. In collaboration with community centers, a teacher education program in a large university in an urban area and a community college, the CMP provides mathematics parent-tutoring virtual sessions in an 8-week program to parents of young children (pre-K to K-5) who wish to receive free tutoring sessions to support their children learn mathematics at home. PTs who participate in the CMP are enrolled in the largest teacher preparation program in an urban area. Tutoring sessions help inform the teacher preparation programs about PTs' readiness to teach mathematics, and the ways in which they enact strategies taught in the programs in the context of developing their teaching practice.

Figure 1 illustrates the ways we have thought about and situated this work. It is worth noting that this is a simple illustration of a very complex system, and it is constantly evolving; however, it does give a sense of how we are viewing this in our area. In our region, the school serves as the hub for formal mathematics knowledge. PTs at our institution are coached in formal school settings and are mentored by university faculty and in-service teachers in these schools. The arrow linking the PTs to the school shows this relationship and illustrates the path from PT to in-service where they are entrenched in formal school settings and PTs work with students in schools. In-service teachers and students coexist in formal school settings, but students live in two worlds: formal school and home/communities. There is evidence 


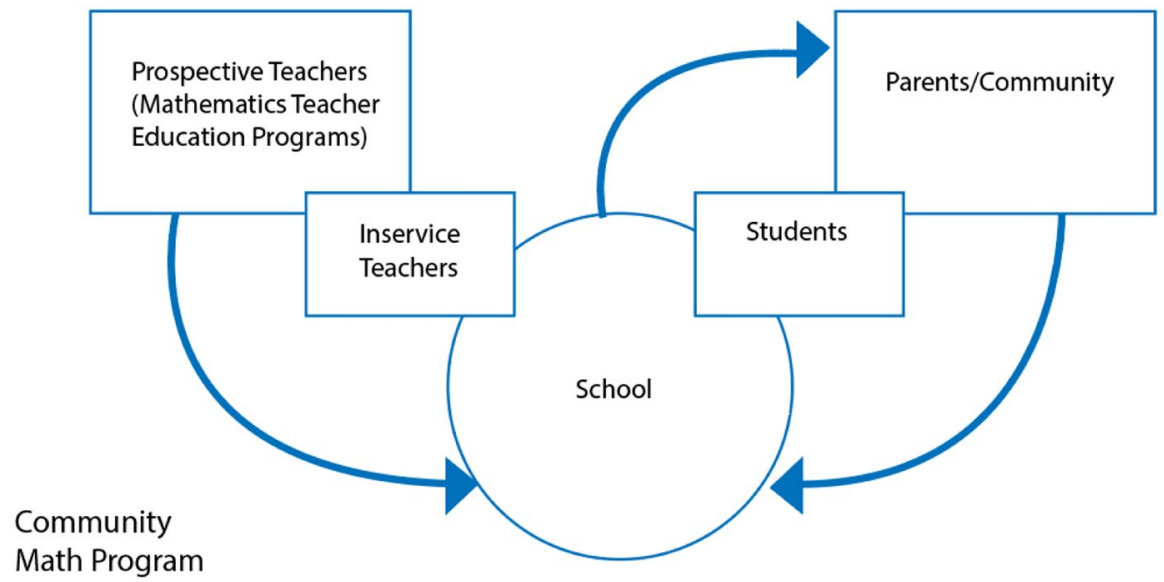

Fig. 1 Conceptualization of formal vs. informal schooling spaces

that these are distinct settings for children with distinct cultures and rules. Teachers and schools communicate with parents and vice versa, indicated by the arrows each way, but this is often mediated by the student (illustrated by the arrows going through the student box), and almost always happens on the school campus.

The CMP is designed to impact PTs so that they are prepared to work in highneed schools, and with parents, who have cultural and mathematical assets that are often overlooked in teacher education programs. When PTs learn to teach mathematics, utilizing community assets and with a parent's perspective in mind, it can transform mathematics education in schools when these PTs become in-service teachers.

Teacher's PET (preparing toward excellence in teaching) program Before being paired with a parent, PTs were coached virtually for 5-6 weeks on sense-making and problem-solving strategies, technologies relevant to their tutoring sessions, and communication strategies within the teacher's PET program. Teacher's PET consisted of 6 multimodal modules and workshops in which PTs had opportunities to learn and enact sense-making strategies, questioning that promote sense-making, and the use of virtual manipulatives, everything in the context of a virtual environment. PTs received explicit instruction on how to use virtual tools and on how to facilitate mathematics content in virtual settings. Teacher's PET utilized representations of practice (e.g., case studies, videotaped sessions of previous PTs tutoring parents, instructional videos to facilitate coaching) and approximations of practice in which PTs had opportunities to rehearse how to teach word problems in a safe space. The coach and PTs provided peer feedback and had opportunities to reflect on how to develop and improve their practice. Further, PTs learned how to utilize information from prior sessions to plan future sessions to build relationships, extend thinking, and promote growth in content.

After coaching was completed, PTs were paired with a parent to begin tutoring sessions. During tutoring sessions, PTs received onsite coaching supports from a 
faculty member, coach, overseeing the project. The role of the coach was to model the enactment of sense-making strategies if needed, provide examples, and assist PTs as they develop their teaching practice. PTs who have been in the program for some time may also serve as a sounding board or coach for newer PTs, providing real-time or reflective advice, guidance, or feedback. PTs also serve as a community of learners and educators, discussing sessions, strategies, and other tutoring-related issues as they arise. Over time, we have found that most PTs need less support and coaching.

Implementation In the fall of 2019, the tutoring program was implemented through community centers instead of traditional school settings. At this time, university faculty were doing the tutoring at one particular community center as a pilot site and to coach one parent to eventually take over the program when we expanded to a second community center. Beginning in spring 2020, PTs anticipated meeting with parents at the community center for tutoring. Thus, 1 week before tutoring started, the COVID-19 pandemic made us rethink how to continue with the program in a virtual environment. PTs designed lessons using virtual tools such as BitPaper, virtual manipulatives, and Zoom, and we provided technology to parents. While this was initially a stressful transition, the outcomes for PTs have been notable, and the program has grown to reach more parents than it would have had we remained faceto-face. Our data for this study focus on the PTs and the implications of this type of program for mathematics teacher education. The research question that drove this study was:

In what ways did engagement in the parent tutoring program support PTs enact sense-making strategies and use virtual manipulatives to promote parents make sense of mathematics?

\section{Theoretical framework}

This study builds on the IDEAL (instructional strategies, design, engagement, approximation of practice, and learning) framework (Author, 2018) which seeks to make connections between what PTs learn in teacher preparation programs to enact and appropriate new instructional strategies in the context of practice. The IDEAL framework draws on the sociocultural theoretical perspective (Dewey, 1904/1965; Ericsson, 2002), the zone of proximal development (Vygotsky, 1978), and follows Pendleton et al.'s (2003) model for feedback interaction. Through three iterative stages-(a) design stage, (b) approximation of practice stage, and (c) appropriation stage-IDEAL conceptualizes teacher learning as a long-term, iterative process that seeks to promote PTs' changes of participation in socially mediated activities (Leont'ev, 1981; Vygotsky, 1978) within a community of practice (Wenger, 1998).

The approximation of practice stage describes the use of scaffolds in the form of approximations of practice and representations practice (Grossman et al., 2009). Approximations of practice provide PTs with opportunities to rehearse aspects of 
teaching in a safe space and to engage in intensive and focused opportunities to experiment with aspects of practice. PTs have opportunities to develop habits of mind and character and new ways of thinking (Shulman, 1998) while engaging in practice that resembles the actual practice of the profession (Grossman et al., 2009). Representations of practice seek to introduce PTs to new instructional strategies by watching video recordings on the enactment of instructional strategies, scaffolds, and content instruction in authentic teaching settings. Representations of practice allow PTs to build from prior knowledge and past experiences to co-construct knowledge alongside a more experienced peer (Rogoff, 1990; Stone, 1993; Vygotsky, 1978). Building from prior knowledge (Vygotsky, 1987) and past experiences (Rogoff, 1990) are anchors from which PTs build new teaching practices. Thus, it provides PTs with tools to reconcile discontinuities between theory learned in the program and the enactment of instructional strategies in tutoring sessions. To co-construct knowledge, PTs meet seeking to be part of a community of practice. These meetings provide opportunities for PTs to deconstruct representations of practice and to reflect on visible and hidden aspects of teaching, while PTs engage in discussions that foster reflection.

The appropriation cycle describes how onsite coaching scaffolds the co-construction of knowledge in coach-teacher interactions as they engage in social activity (Bruner, 1986). Onsite coaching is described as the one-on-one and group support that PTs receive from a more experienced practitioner (coach) to assist them in the appropriation of pedagogical tools. Onsite coaching supports PTs enactment of new pedagogies and promotes dispositions for continuous improvement (Darling-Hammond, 2006; Grossman, 2005; Zeichner, 2010) because it supports PTs in confronting the complex aspects of teaching (Little, 1990). In this framework, coaching is in the form of modeling. Modeling is described as demonstrations of enactment of instructional strategies by a more experienced coach. Modeling allows PTs to receive immediate feedback and aims to prompt the PTs to recognize pedagogical tools that can have positive effects on students' learning because it makes practice salient and visible.

This theoretical framework is appropriate for this study because it explains how features of teacher learning support PTs' enactment and appropriation of instructional strategies. Further, IDEAL explains the phenomenon on how PTs use representations of practice, approximations of practice, and modeling through a trajectory of participation. In relation to teacher learning, this framework emphasizes agency of PTs while situating learning in social contexts because it allows PTs to learn beyond university coursework and what is learned in the community of practice, because learning is extended to tutoring sessions.

\section{Methods}

This is a mixed methods study with a two-phase, sequential exploratory design (Creswell, 2009; Leedy \& Ormrod, 2013) due to its emphasis on qualitative data. For the quantitative portion of the study, we used pre- and post-tests measures to assess PTs' mathematics knowledge before they started the program and after 
having gone through training and tutoring parents. For the qualitative part, we used an embedded case study with eight units of analysis (Yin, 2014) to assess how PTs participation in the parent-tutoring program supported the enactment of sensemaking strategies and the use of virtual tools. Focusing on a small number of PTs allowed us to analyze the phenomenon closely as PTs enacted sense-making strategies in virtual settings throughout a year. Participants in the spring 2020, summer 2020, and fall 2020 semesters were 8 female PTs. Three of these PTs participated in the study for 3 academic semesters, one of them for 2 academic semesters, and 4 for 1 academic semester. Six PTs identified themselves as Hispanic, one as Caucasian, and one as Indian. Six PTs were bilingual in Spanish and English, and 2 spoke English only. All the participants sought certification in education, 4 in early childhood education (ECE)-6th grade bilingual education, 2 in ECE-6 general education, 1 in ECE-6 English as a second language (ESL) education, and 1 in 4-6 ESL education.

The settings for the study were virtual environments created during the COVID19 pandemic. These were fluid and unique environments, and many variables contributed to the particular settings on a certain day. Our goal was to look for trends and outcomes across settings and participants to determine what we could conclude and generalize for the project. Our approach to this study was to systematically observe and analyze the ways in which PTs were demonstrating teaching practices during their participation in the parent tutoring program. Pre- and post-test measures were administered at the beginning and end of each cycle. The pre- and post-tests measures included a content test and a practical skill assessment where they were asked to represent problems in multiple ways. The content test consisted of 10 mathematics operations which assessed PTs knowledge on fraction operations, decimals, integers, order operations, and three word problems in which PTs had to identify relevant information to solve the problems by using manipulatives. We used a $t$ test to analyze this data.

For the qualitative data, we employed a multi-level thematic analysis to determine themes that emerged and recurred throughout the data set (Lapadat, 2010). We followed Braun and Clarke's (2006) 6-phase guide as a general framework for data analysis and utilized inductive coding to uncover themes. Data analyzed include 10 hours of videos from 5 preparation sessions, 168 one-hour videos from all coaching sessions, 168 BitPapers from tutoring sessions as artifacts, 16 hours of transcripts from one-on-one semi-structured interviews with each PTs which took place in the sixth tutoring session, and 2 hours of transcripts from a focus group interview to PTs at the end of the tutoring sessions. We mapped inductive themes onto the AMTE standards (2017) to support our assertion that indicated the development of mathematics practices for beginning teachers of elementary school mathematics.

While themes did not perfectly map one-to-one, there was significant overlap in emergent findings. We found that PTs showed progress in the following dimensions: (1) content and pedagogical content knowledge (scaffolding content in ways that connected to prior and future knowledge); (2) articulating positive dispositions towards mathematics and talking about content; (3) developing a core set of pedagogical practices centered on communication, collaboration, and knowledge of student; and (4) abilities to understand, utilize, and connect to student funds of knowledge. We present these below with data to support each theme, and note that 
while these are distinct categories, there is significant overlap in the demonstrated skills within each. As such, it is clear that these mathematics teacher educators' (MTE) understandings interact in some way, and we present the way in which our data show this happening; however, more work in this area is needed to refine this generalization.

\section{Findings and discussion}

Our goal for this project was to understand the ways in which PTs develop skills related to elementary mathematics teaching in the course of a parent tutoring project. The larger goal of this study was to add to the literature in mathematics teacher education around experiences MTEs can engage PTs in developing these types of skills. PTs were given sustained opportunities to learn mathematics throughout the program during their coaching and tutoring time. They also engaged in partnerships with parents and other community members and deeply engaged in planning and engaging parents in meaningful mathematics. While PTs contextualized tutoring sessions to parents' cultural backgrounds and prior knowledge, they considered sequencing and scaffolding, relevancy of the content, task development, and building towards common mathematical practices. We believe the focus on sense-making allowed PTs to attend to all of these things in a holistic manner, and we discovered that these are enacted into fieldwork/formal teaching settings. Thus, we found that the onsite coaching and tutoring experiences, which were grounded in the IDEAL framework and thus included onsite coaching and other supports, were formative in developing essential skills for teaching mathematics in elementary school, particularly in the following areas. We begin the description of each section with an excerpt from the Association of Mathematics Teacher Educators' 2017 Standards for Preparing Teachers of Mathematics to show how the CMP directly addresses these.

\section{Content and pedagogical content knowledge}

Well-prepared beginning teachers of mathematics...understand foundational mathematics concepts that they will teach, and they connect those concepts to mathematical practices...[They] develop pedagogical knowledge and practices to cultivate students' mathematical proficiency...[and] use technology tools, physical models, and mathematical representations to build student understanding of the topics - AMTE Standards, 2017

We used both quantitative and qualitative measures to determine PTs growth. Pre- and post-test measures included a content test and a practical skill assessment where they are asked to represent problems in multiple ways. On the content measure, PTs showed growth. A dependent sample $t$ test was conducted comparing the pre- and post-test results of PTs. On average, PTs in the spring 2020 scored higher on the post-test than on the pre-test $(M=6, \mathrm{SD}=6.315)$. Tested at the $95 \%$ confidence level (CI) was not significant, $t(4)=0.95, p=0.206$. On average, PTs in the summer 2020 scored higher on the post-test than on the pre-test $(M=5, \mathrm{SD}=5.24)$. 


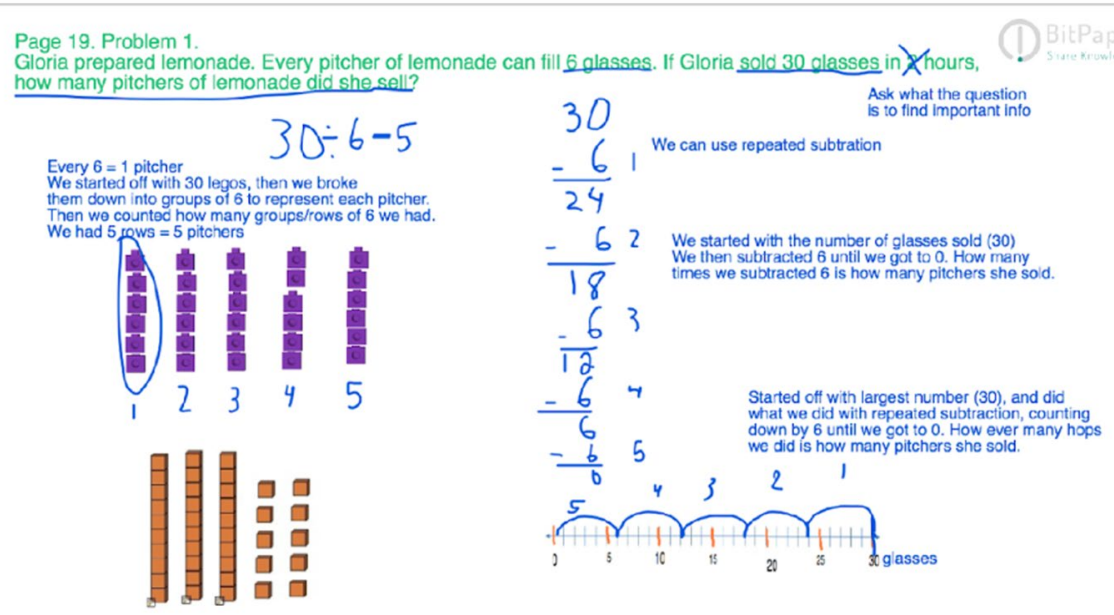

Fig. 2 Ashley tutoring Reina on week 2

Tested at the $95 \%$ confidence level (CI) was not significant, $t(5)=0.953, p=0.197$. PTs in the fall 2020 scored higher on the post-test than on the pre-test $(M=37.75$, $\mathrm{SD}=5.718)$. Tested at the $95 \%$ confidence level $(\mathrm{CI})$ was significant, $t(4)=6.602$, $p=0.004$. While this is a small sample size, we did want to show the growth in content among PTs, as it is notable.

PTs also demonstrated systematic growth in developing skills related to elementary mathematics teaching as they had more field experiences to enact sense-making strategies. PTs began to discuss and incorporate connections across concepts and using those to develop models and tasks for subsequent tutoring sessions. For example, in Fig. 2 below, in the summer 2020, Ashley ${ }^{1}$ (PT) tutor and Reina (parent). On the left, we see that in week 2, Ashely and Reina are working on using the visual representation of Unifix blocks and number lines to solve a division problem. Ashley supported Reina's understanding of division by relating it to repeated subtraction. In Fig. 3 on week 7, Ashley has designed a task that leveraged Reina's understanding of multiplication of fractions by using realistic virtual manipulatives and area models. This provides an interconnected approach to developing mathematical skills and a deeper understanding of content on the part of the PT.

This type of evidence demonstrates PTs developing understandings about how a student constructs knowledge and the ways in which they can develop tasks to promote productive struggle but also leverage prior knowledge. This also shows a belief among the PTs in the necessity of constructivism and the value of making meaning through discourse and shared problem-solving. There is also scaffolding evident throughout the data, showing that PTs are developing understandings about how to identify how concepts develop over time. In many ways, tutoring parents afforded

1 All names are pseudonyms. 


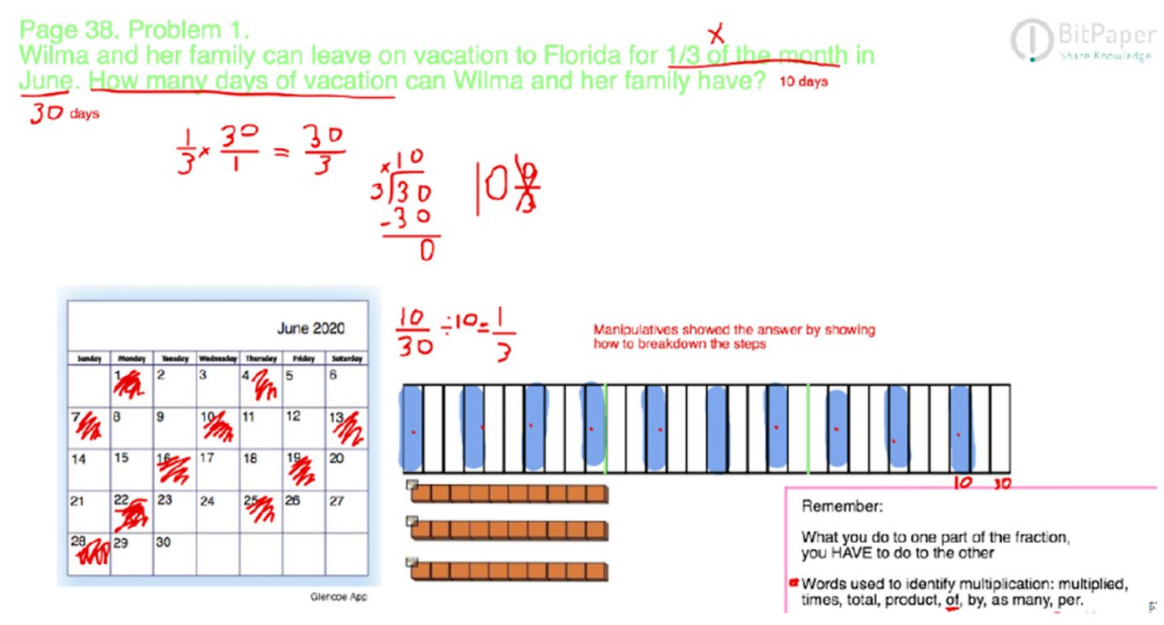

Fig. 3 Ashley tutoring Reina on week 7

them more opportunities to see this, as they moved more rapidly through the program curriculum than they likely would have with a school-aged child.

PTs have shown significant growth in representing problems and solutions in multiple ways. When compared to performance before the coaching/tutoring program, PTs were able to show more ways to solve a problem and were able to more effectively connect these representations. One portion of the pre-testing, for example (Figs. 4 and 5), asks PTs to represent three different ways to solve a particular problem, in this case $46+72$. Every PT used traditional methods to solve the problem on the pre-test (line up numbers, start from right hand side, etc.). On the post-test, PTs were able to show at least three different ways to solve the same problem using tools and varied conceptual representations.

This shows increased attention to and utilization of anticipated student responses. Since PTs are enacting this practice in their sessions, it develops in ways that will translate to the classroom. Moreover, PTs practiced asking strategic and scaffolded questions that would elicit these responses from participants.

\section{Development of core pedagogical practices}

Well-prepared beginning teachers of mathematics have begun to develop skillful use of a core set of effective teaching practices...[and] enter classrooms with commitment to, and initial skills for, enacting effective mathematics instruction. - AMTE Standards, 2017

Throughout the program, PTs showed growth in their depth of thinking in the planning, implementation, and analysis of instructional sessions. Sustained engagement in these processes provided a foundation from which PTs could build effective teaching habits centered on sense-making, discussion, and problem-solving. From the beginning of the coaching cycle, PTs in the CMP were focused on sense-making 

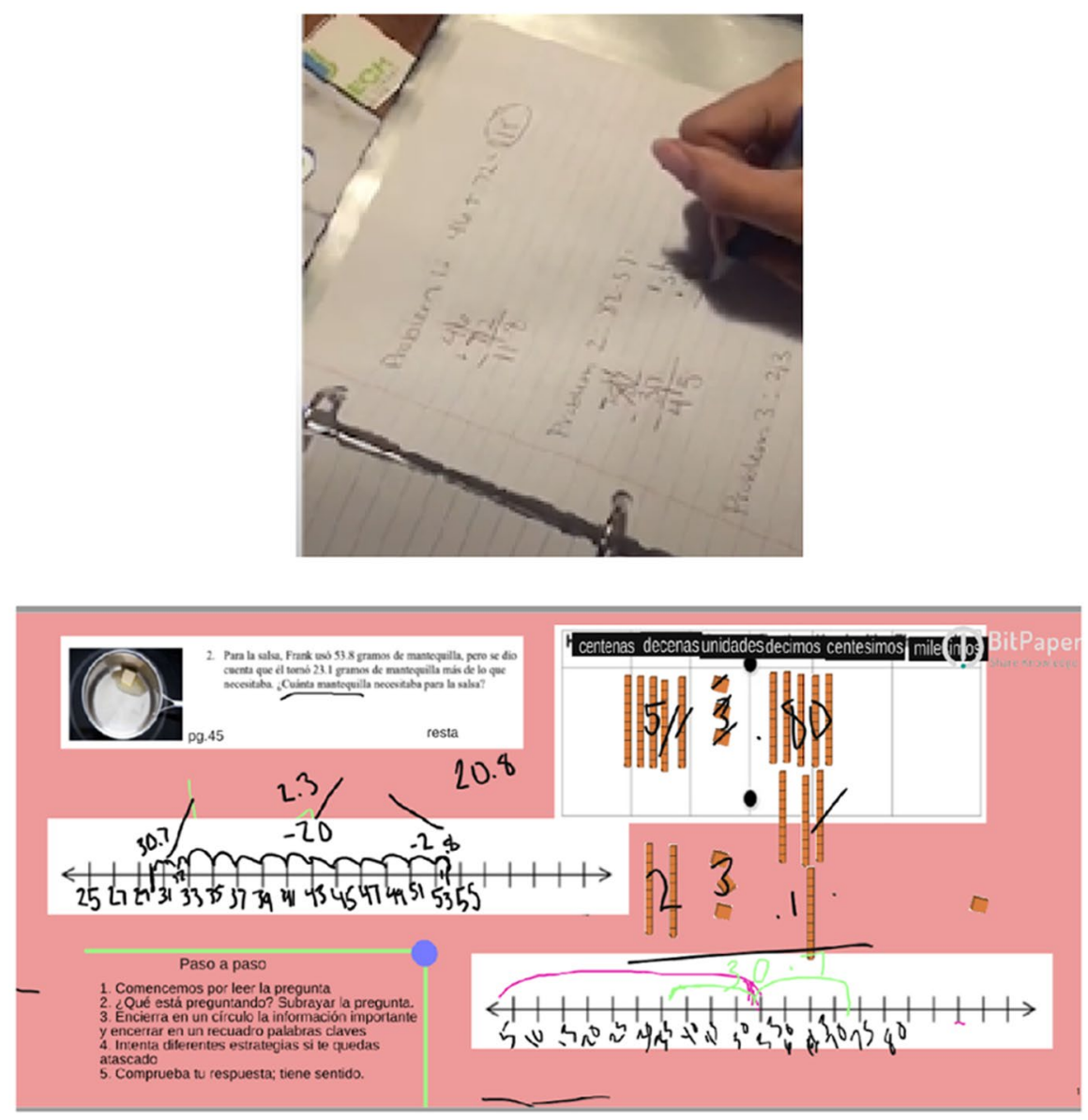

Fig. 4 Delia's pre- and post-test

in mathematics and effective questioning. As such, the practices we encouraged and modeled reflect these foci. Over the course of data collection, there was evidence that PTs developed a set of core pedagogical practices through their work with parents (Table 1). PTs worked collaboratively to develop these in the coaching portion of the program and practiced them with each other before implementing them with parents. Through observation, we generalized these to potential classroom practices that PTs were practicing in the course of the project. Over time, each PT modified these core practices to fit the needs of the parent the PT was tutoring; however, the sessions served as continued rehearsals of these practices and allowed for these modifications. Ultimately, PTs were making decisions about these practices based on evidence and were differentiating the ways in which the practices were enacted based on the parent's needs.

We were struck by how ingrained these practices became in PTs practice with parents. We considered that an affordance of learning to teach mathematics in this 


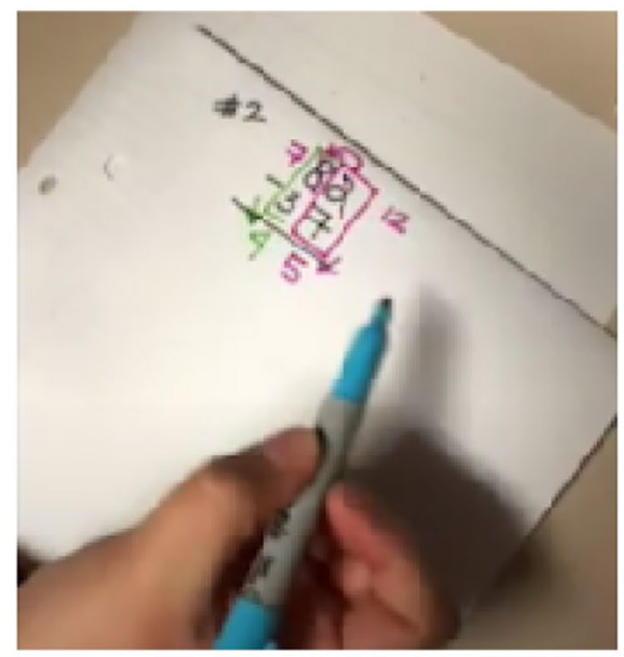

Los amigos de Andrew también decidieron traer comida. Si cada uno trajo 4 rebanadas de pizza y 3 boleperstritos, ¿cuántas rebanadas de pizza ienen en total?

4 grupos de 4
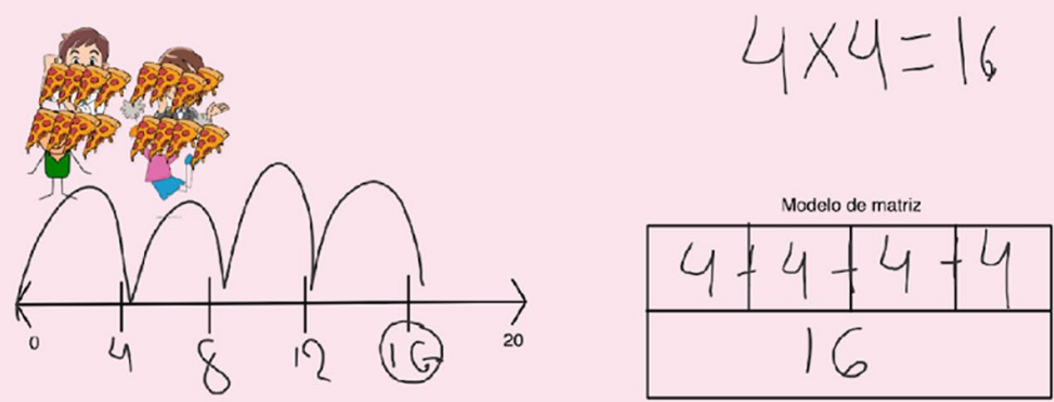

Fig. 5 Elsa's pre- and post-test

setting is that outside of the traditional school setting, PTs may be more willing to try innovative ways of teaching mathematics. Since they were not working with a traditional student, and because parents communicate if something is unclear, it was evident when a PT needed to shift or change a practice. Delia was an example of a PT who helped develop the essential practices and had enacted them through several tutoring cycles. We consider Delia a leader in the program and saw her modify the practices with different parents to best meet their needs. In one session near the end of the final cycle of data collection for this paper, Delia tried a new approach of teaching decimals that did not draw on the core set of practices, and she did not focus on her parent's sense-making while solving the problem. Delia did not use 
Table 1 PTs core practices and potential classroom practices

PTs core practices

Develop mathematical goals based on prior session

Make a personal connection at beginning of session (and throughout); use what you learn to develop relevant tasks

Parental engagement

Collaboratively underline/circle/note important information in the problem; ask questions to elicit their thinking about the problem

With access to any manipulative, ask the parents to represent their thinking

If the strategy will not lead to a correct solution, use questioning

Ask parent to solve another way, using another representation; use questioning

Collaboratively connect the solutions

sense-making strategies or questioning, rather she focused on explaining a procedure by using a top-down approach (Fig. 6). Delia indicated that, since she is currently student teaching, she was trying out a practice that she was learning about in that more formal setting. Observation notes and a debriefing session with Delia indicated that the parent was very confused by the lesson and that the practices Delia attempted did not help the parent to make sense of mathematics. The parent expressed, "No, I am very confused. I have no idea how to explain this to you." This is not to say that the practices listed above are the only practices that will lead to sense-making, but rather to highlight the importance of developing a core set of practices that are (1) developed collaboratively by teacher and student, (2) suitable to the learning goals of the classroom, and (3) adaptable based on need. When Delia tried to implement a set of teaching practices that were given to her by someone else, she was less prepared or able to engage the parent in sense-making.

From these essential practices, we saw that PTs were enacting research-based strategies for instruction. For example, the process of generating a relevant problem,

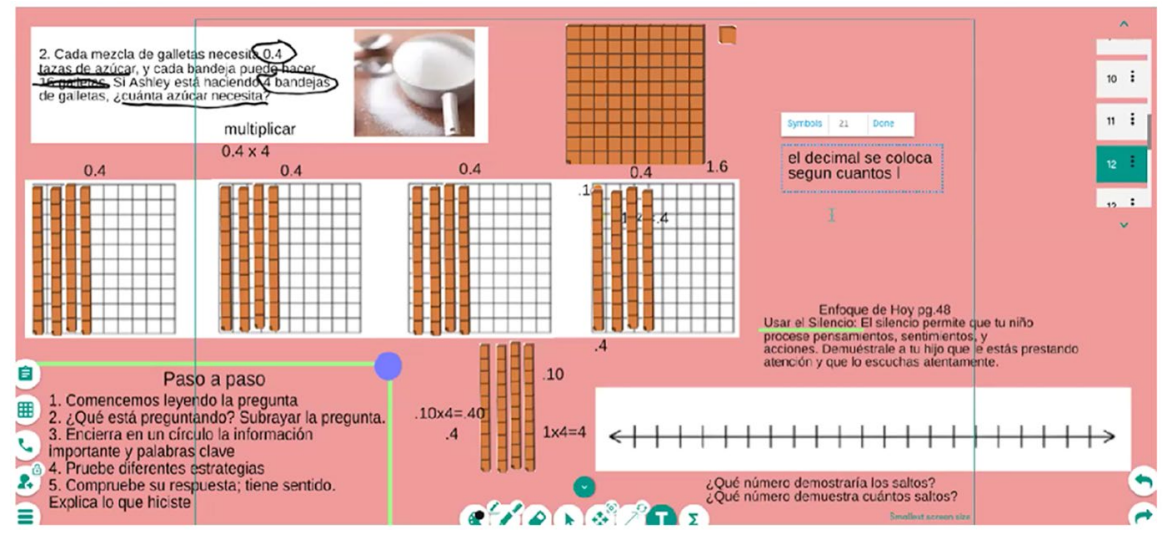

Fig. 6 Delia using a top-down approach when tutoring 


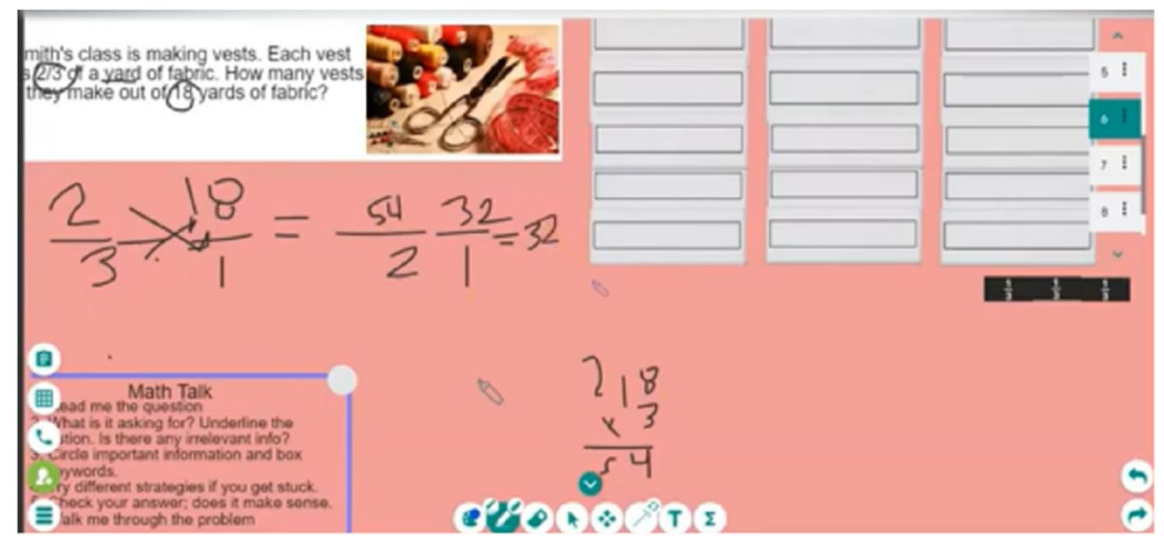

Fig. 7 Division computational error

anticipating student responses, eliciting multiple representations through questioning, and connecting across these representations became routine. This ability to generate and engage in a productive mathematical discussion (Stein et al., 2008) was a notable outcome of the project. PTs also demonstrated a shift in their approach to questioning around errors. In beginning sessions, PTs were more likely to indicate if a solution strategy was incorrect using voice inflection or interruptions. For example, one parent was given a problem that asked her to write a multiplication problem based on a picture of 4 groups of 3 balloons. Initially the parent wrote $6 \times 6=36$. Ashley, the PT, did not correct the error, but instead asked the parent to explain how she got the answer of 36 . The parent immediately recognized that her answer did not make sense and corrected her equation to $4 \times 3=12$. Ashley then asked her to explain the answer and waited until the parent said "there are 3 balloons each in 4 groups" to which Ashley said, "yes, another way to think about multiplication is as repeated addition."

In later sessions, summer 2020, we saw Delia allowing parents to work through solutions regardless of the accuracy of their answer, and each PT used questioning when scaffolding was needed. If there were errors, PTs utilized these to elicit thinking around the error and leveraged that thinking to launch new tasks or discuss the concepts embedded. In Fig. 7, the parent, Amy, made a division error, concluding that $54 \div 2=32$. Delia asked the parent to use fraction tiles to solve the problem (Fig. 8). The parent used $\frac{1}{3}$ tiles to represent the yards of fabric that she needed. Amy expressed that she needed to see the number of $\frac{1}{3}$ tiles that fit in each tile mark. After counting the fraction tiles and multiplying $1.5 \times 3=4.5$ and $4.5 \times 6=27$. Amy noted that her first answer of, 32, was different from her answer when using the fraction tiles. Amy revisited her equation because she was sure that the 27 was correct because she could see the representation of the fractions with the virtual fraction tiles. When Amy divided 54 by 2, she realized she made a simple computation error, and the answer was 27 , and shared, "It's a pretty amazing feeling when you catch your error. I have to say that." In this example, making connections across 


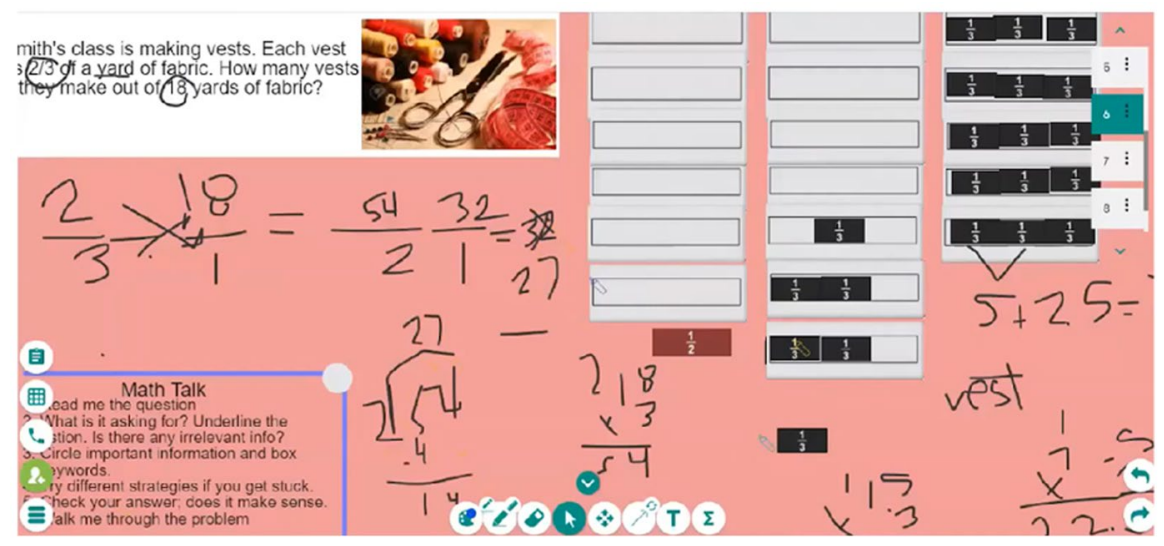

Fig. 8 Self-correction of an error by making connections across representations

representations allowed Amy to self-correct, to see where her error was because virtual fraction tiles allowed her to have a visual representation of the yards she needed for each vest.

Errors, in other words, were simply evidence of what the parent knew about mathematics and were used to make decisions about instruction. Coaching on error analysis through videos helped PTs to develop these skills. If answers were correct, PTs still asked parents to explain their reasoning, thus making this a routine practice. Ultimately, observations showed that PTs were focused on the goal for the parent to learn more based on what they have done and build on prior knowledge.

\section{Funds of knowledge approaches and collaboration with families}

By connecting with parents, well-prepared beginners engage in the mutual sharing of resources and ideas to support the mathematical development of young learners...[and] demonstrate interest in learning in how their children and their families use mathematics at home and in their communities. - AMTE Standards, 2017

Funds of knowledge (FOK; Moll et al., 1992) is central to the CMP, and the design of the program is founded in FOK approaches. As we have mentioned, one purpose of the project was to capitalize on the knowledge and resources that parents bring to mathematics (Civil \& Andrade, 2002) and use these as resources in the classroom. We have found that in many of the schools in our area with high populations of traditionally underserved students, teachers adopt (or are instructed to adopt) a more scripted method of teaching mathematics. More specifically, mathematics is often taught in isolation and without relevant context. The contexts that are used may leave some students struggling to find connections between home and school mathematical practices. We aimed to work outside of this setting in part to provide PTs with the freedom to become knowledgeable about the home-based 
mathematical knowledge that exists in these communities and utilize this in instruction (Moll \& Greenberg, 1990). Given the shift to virtual learning, PTs effectively engaged in home visits each time they held a tutoring session. Often, parents would move around the house to attend to other things at the same time they were engaging in the tutoring. Their children were in the background and at times in the frame. One parent rocked her baby to sleep while working problems with her tutor. This allowed tutors to learn about parents' practices at home, and helped to develop PT knowledge about parents' lives that enhanced communication practices, which in turn led to relationships and trust among the groups.

Development in this area was evidenced throughout the program. Teacher's PET encouraged PTs to develop home activities that allow parents to connect mathematics learned in tutoring sessions to activities that parents could do with their children at home. PT Malki, for example, was working with parent Rosa on fraction concepts during one session. Rosa shared a story about rice and tomato paste and how she now purposely uses fractions in her cooking. In this example, she explained to Malki that her daughter noticed that the rice was "less red than normal...how much tomato paste did you use" to which Rosa replied that she used "about $\frac{1}{3}$ of the can." Her daughter then said, "but usually you use $\frac{1}{2}$ of a can, isn't $\frac{1}{3}$ more than $\frac{1}{2}$ ?" Rosa said, "I looked at her and said this is a learning opportunity right here, and I took out the manipulatives that you gave me... and I showed her this is what $\frac{1}{2}$ looks like... and this is what $\frac{1}{3}$ looks like." She then asked her daughter which one was bigger, and the daughter understood that $\frac{1}{2}$ was greater.

In a different session, PT Ashley asked parent Tina to share how she used the home activities from the previous session at home to practice mathematics. Tina shared that used the home activity to connect the concept of equivalent fractions to her thinking about a pizza. Where Tina orders from, she explained, they usually cut a pizza into 8 pieces, but she "double-cuts" the pizza for her kids which creates more pieces from the same whole. She indicated that her thinking about equivalent fractions was connected to this practice and laughed as she explained that she tells her children they are having 2 pieces, but it is $2 \frac{1}{16}$ instead of $2 \frac{1}{8}$. One day her daughter was acknowledging that understanding, and Tina was able to connect CMP to this common activity.

\section{Dispositions towards (teaching) mathematics}

Well-prepared beginning teachers of mathematics...demonstrate positive attitudes toward mathematics as a discipline and productive dispositions toward the teaching and learning of mathematics. - AMTE Standards, 2017

Over the course of the project, there was a noticeable shift in PTs' dispositions towards teaching mathematics. This was evident in various areas and became more pronounced the longer a PT remained in the program. Ultimately, these dispositions contributed to the PTs feeling that they do belong as mathematics educators, and more strikingly, this also seemed to resonate to parents. For example, Ashley shared that she learned mathematics by drilling, solving worksheets, and 
following pictures. Ashley was not aware of the use of manipulatives to solve problems or that reflecting was an option. Ashley expressed,

I thought teaching was not for me, I didn't think I was good at it. Now I

LOVE IT!!! I get it more! I allow my students to unpack word problems, and use questioning and modeling to help them make sense of mathematics

Ashley changed her dispositions toward teaching mathematics and expressed her willingness to teach by "focusing on students' responses", "asking for help to peers, watching videos on how other PTs teach, using manipulatives because they allow to make sense of math", and by solving the same problem in multiple ways. Similarly, María shared her renewed excitement about teaching mathematics, "Before the program, I was kind of nervous about just teaching math in general because I've always struggled with math a lot. Now, I feel so much more confident with going into a classroom and teaching math." María's disposition about learning mathematics changed because throughout the program, she developed preparedness and confidence about mathematics.

María and Ashley had the same perceptions on the use of questioning to supports students' sense-making,

I use questioning to get to know where students are at, to get them to answer the questions without giving the answer away, and because I want to know what students are thinking

María's dispositions on how to teach changed from telling students what to do to supporting them, making connections, building confidence, and developing understanding.

Another example is Elsa; she shared how her dispositions about teaching and learning mathematics changed throughout the program. Elsa expressed that prior to the program, she would use a top-down approach to teaching, but her students were neither interested nor engaged in the session,

That's when I noticed the parents were more engaged. They were like, oh, this is what we do, and that's how I noticed. I tried it multiple times when I was doing my field experience too

Elsa made changes in her teaching practice, not only when tutoring, but in her field experiences because she saw positive changes in relation to students' engagement and mathematics sense-making.

Elsa's dispositions toward learning mathematics also changed. Even when Elsa argued, "I think math is my strong suit. I've always gotten very high grades in math", she has always struggled with word problems, "I would try to avoid them as much as I could. Word problems just confused me." Elsa's disposition toward word problems changed when she realized that sense-making strategies such as underline relevant information, breakdown the problem, and use manipulatives supported her and her students to make sense of them.

PTs' dispositions toward learning and teaching mathematics changed throughout their participation in the program as they developed understanding of 
mathematics and had opportunities to enact sense-making strategies that promoted engagement and evidence of learning for PTs and parents.

Reframing mistakes In the initial coaching portion of the program, PTs are often anxious about the mathematics content, and whether they "know enough" to tutor a parent. PTs vocalized that they were concerned about making a mistake in a tutoring session, similar to how many novice teachers worry about the same thing in front of a group of elementary school children. Over the course of the program, PTs were much more willing to pause when they caught an error (from their own preparation or from the parent) and engage in questioning to encourage sense-making. This demystified certain accepted mathematical practices for PTs in that they realized that what are often called "mistakes" or "misconceptions" are actually opportunities for deeper learning. For example, the program allowed Ashely to change her mind set about teaching and wanting to teach as a career. In the program, Ashley learned to focus on parents' responses, co-construct knowledge as she worked with her peers, and watched videos on how her peers teach. Further, Ashley learned that "there is not only one way to solve a problem" and that she can support her parents' sensemaking by using virtual manipulatives and questioning. Ashley shared, "I thought teaching was not for me, I didn't think I was good at it. Now I LOVE IT!!!” This was certainly in part because the coach framed "mistakes" in this way, but we saw evidence that PTs were enacting the content in their own practice. In working with each other during coaching and then with parents in tutoring (onsite coaching), PTs were rehearsing what they might do in case they make an error in front of a class. Instead of quickly moving on or making up a reason for the mistake, which can often lead to student misconceptions, PTs were more likely to stop and re-think the task, the solutions, or whatever part of the discussion they are working on. Moreover, they acknowledged their own mistakes, empowering the parents to make their own as a means to learn more.

Emphasis on sense-making Our approach as MTEs is to reframe mathematics as a sense-making activity rather than a series of steps. In other words, PTs were encouraged to approach mathematics as a tool to make sense of the world around them. An emphasis on the concept rather than procedure becomes more pronounced among PTs, in their own work and in their work with parents, throughout the program. Elsa, one of the PTs in the study, indicated that prior fieldwork experiences had not prepared her on how to support students to this level of precision. These general experiences “don't really go into depth and how we can actually help with like a student... [but this program] has really helped me like getting into a student's brain I guess." Before the program, Elsa indicated that she would "talk most of the time" during a session to explain ideas, but parents were "not really interested." When she "switched the whole method around" and began emphasizing sensemaking as a central focus, the parents became more engaged. Elsa indicated that she has since used these strategies in her fieldwork placements. This semester, for example, she was with a teacher who indicated that she "did not like anything about math." Elsa noticed that students were not engaged in lessons and that the teacher was teaching procedures. When Elsa was able to work with a small group of these 
students, she used the questioning strategies "like how we do it with the parents... and all of a sudden they were all super engaged."

Similarly, when reflecting on the program, PT Elsa stated that "the thing that shocked [her] most was... we all grew up [as] teachers." She connected what she learned through the sessions to future classroom practice, explaining that "instead of just telling them how to do [a problem], like let them figure out how to do it." She recognized that scaffolding is often necessary, and that teachers can "throw hints at [students] so they can find the way that best fits them on how to solve [a problem]." She goes on to indicate that "it's not just the parents...like it's better to teach kids that way." This indicates that PTs view these sessions as rehearsals for classroom teaching with children and see strong connections between the ways they teach parents and the ways they can teach children. Below we have one excerpt from tutoring sessions that illustrates the ways that these strategies are being utilized by tutors. Tutors encouraged parents to read the word problem out loud and to identify relevant information. Then, the tutor uses questioning to support the parent's sense-making,

J: Oh I'm sorry, and then I'm going to do half of another kilogram

E: Okay, only half?

J: Yeah, only half.

E: How come you're only going to do half?

$\mathrm{J}$ : Because it says, we got the number four here. So that would be the whole and then half of soil, I would think it's half because this half.

E: What is what is one box? Why what is one of the purples squares?

J: She had four and a half kilograms of soil. So actually, I say half of a kilogram because right here it has two right here. It just shows a half kilo. So would that be what I'm talking about? I'm doing two because that's half of the kilo. Does that make sense? Four, so, I'm going to shade in four of these completely and then the half at the end. All of them all of that, right?

E: What does that represent?

J: Initiated 1, 2, 3, 4 kilograms, which be for the four, and then the half will be the one at the end. That will complete that four and a half kilograms of soil.

E: Alright, what's the next thing that we're going to do?

J: Okay, so she used two thirds, two and three fourths kilograms, so I'm going to unshade. I don't know why I shade them all. I'm going to unshaved two kilograms....

E: How did you get one and three fourths?

J: The kilogram, the one that she has is full, it's shaded fully. So that's that's complete for one whole kilogram. And then she has three that are just kind of wandering off there that I see that you know is missing one bar to be completely four I mean one full kilogram. So if I use one of these areas of a kilogram and shade it three of them, she would have three out of four shaded. So that's how I would get. Yeah. 


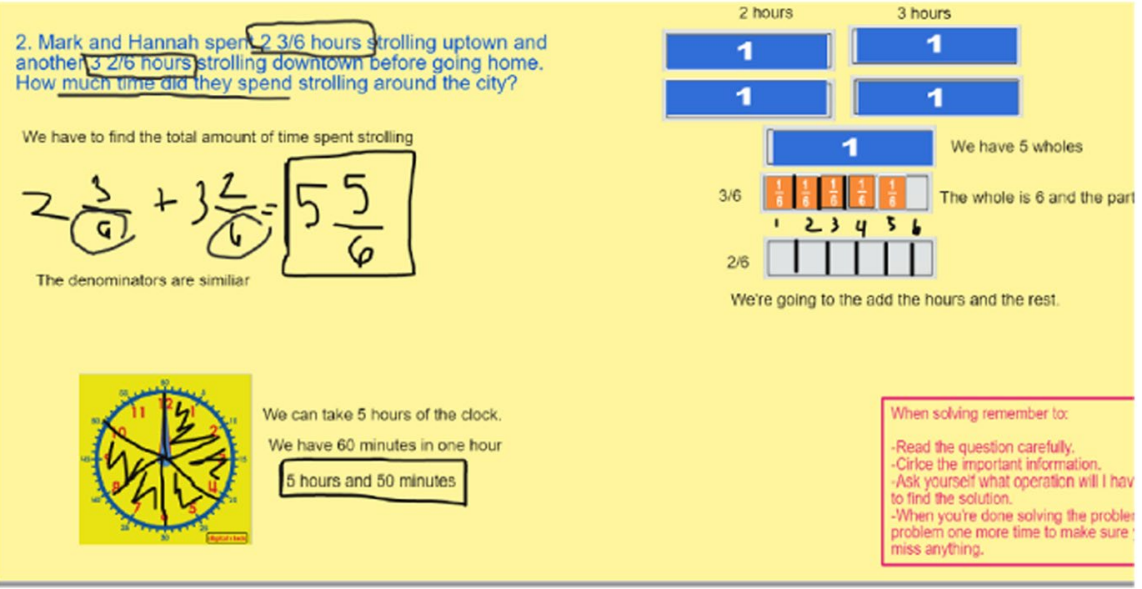

Fig. 9 Week 6: Malki teaching addition of fractions

In this excerpt, Elsa supports Jane to make sense of fractions by using questioning. Notice that the larger blocks of speech belong to the parent, Jane, and Elsa is using questioning to guide Jane's thinking about the problem.

Co-constructing knowledge PTs were consistently interacting with one another and with their coach throughout the program. In the initial coaching portion, experiences were intentionally structured to provide spaces where PTs could work together to solve mathematics problems and analyze parent's solutions to similar problems. We found that this built a sense of community and that this was essential to shifting dispositions towards the ways in which we can do mathematics. In focus group interviews, PTs indicated that one of the most beneficial parts of the program was learning from and with their peers. PTs did this in several ways. During workshops with approximations of practice, they rehearsed teaching with each other and watched videos of prior tutoring sessions-representations of practice-so that they can analyze and discuss specific problems and teaching moments. PTs noted that this helped them greatly because they could view a prior tutoring video to help them think about what to expect as far as responses and iterate on that. In the subsequent tutoring session, we saw evidence that PTs did take ideas from the videos and discussions and built on these depending on what their parent needed. This practice allowed them to co-construct lessons with others and practice the important step of anticipating likely responses.

Other examples of this occurred across PT tutoring sessions. Ashley was an experienced tutor, and Malki joined the program recently. On week 6, PTs were learning how to use fraction tiles, fraction circles, and area models for fraction operations. In her weekly tutoring session, Malki supported her parent to make sense of adding fractions by using three strategies - fraction tiles, tile marks, and a digital clock (Fig. 9). The coach shared the video on how Malki used these virtual manipulatives 


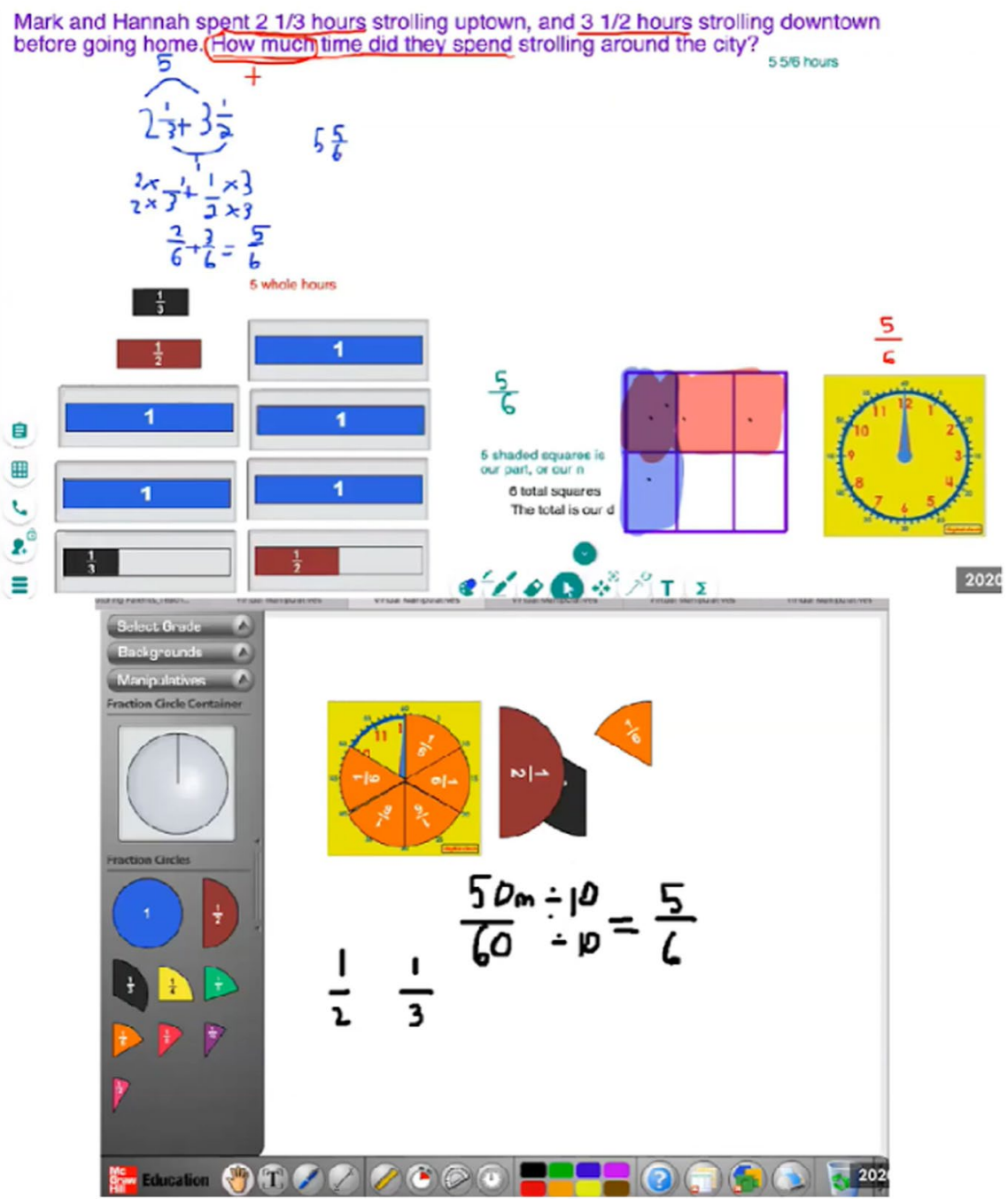

Fig. 10 Week 7: Ashley teaching the same problem with area model and Glencoe

and encouraged other PTs to enact such strategies. On week 7, Ashley built from Malki's ideas on the session and used the same problem from the video. Ashely was willing to learn from Malki even when Ashley was a more experienced tutor. Ashley built from Malki's session and used fraction tiles and the Glencoe app to overlap fraction circles over the virtual digital clock. Ashley also used an area model to add the fractions (Fig. 10). On week 8, the coach shared Ashley's tutoring session, and this time Malki learned from Ashley's session. Malki used fraction circles and the digital clock from Glencoe and an area model to subtract fractions (Fig. 11).

In these ways, PTs were co-constructing knowledge about content and pedagogy throughout the program. This speaks to the development of PTs' dispositions as 


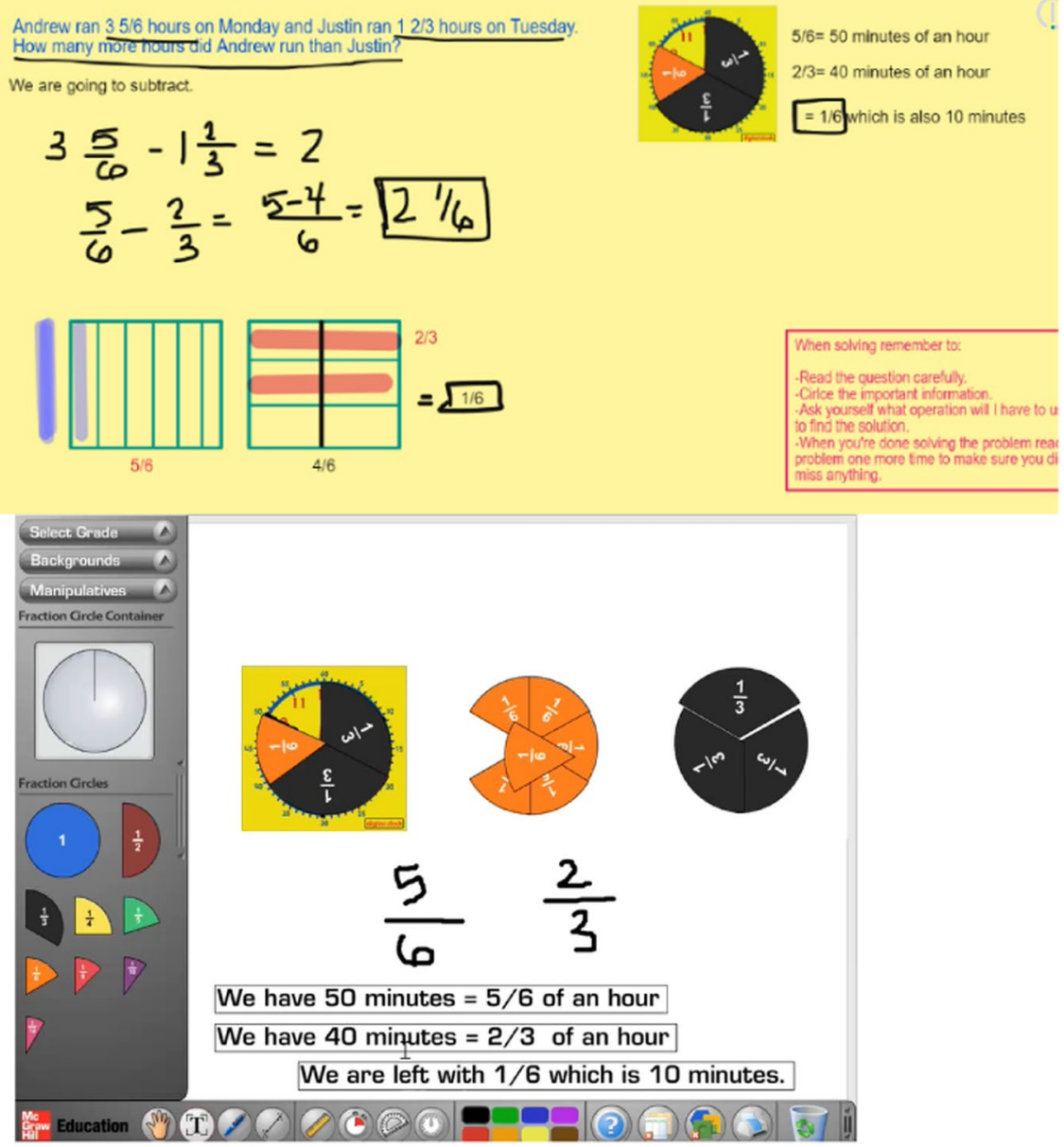

Fig. 11 Week 8: Malki teaching subtraction of fractions with area model and Glencoe

lifelong learners and acknowledging the iterative nature of teaching. This also speaks to PTs' dispositions towards power in the classroom. They viewed feedback from each other, and from parents, as positive. This, coupled with the sense-making strategies that centered the parent's ways of thinking during the sessions, dismantled issues of status that can often occur in mathematics classrooms. Moreover, this encouraged discussion and reflection among PTs and resulted in a fluid power dynamic that was beneficial to everyone. 


\section{Implications}

In this study, PTs used questioning and engaged in dialogue (Diaz-Palomar et al., 2011; Flecha, 2000) with parents to support sense-making and the development of mathematical thinking. Dialogue promotes self-correction and sense-making. We found that the creation of meaning is through dialogue and negotiation as participants share their arguments and create meaning. Egalitarian dialogue provided spaces for parents to engage in discussion on problem-solving and validate their reasoning (Civil \& Bernier, 2006).

This work has implications for MTEs in various settings. Ultimately, our findings show that providing PTs with targeted experiences that allow them to develop specific skills around sense-making, questioning, scaffolding, and discussion is essential to their growth as mathematics educators. We found that traditional field placements at our home institution do not always provide these types of opportunities for various reasons. PTs indicated that their cooperating teachers often do not utilize sense-making strategies in their elementary classrooms, making it difficult for PTs to rehearse these practices with students. This creates a disconnection between the theory that they are learning about in methods courses, for example, and practice with children. This may lead to a regression back to more traditional techniques that are modeled in the fieldwork classroom, as this gap can be difficult for a novice to overcome. We did find that when PTs engaged in the CMP, which does have a specific focus on sense-making and coaching them through the process of learning to teach using research-based strategies, they were more likely to enact these theories into practice, even in a fieldwork class that did not embody these practices. As such, it is vital that MTEs at the postsecondary level advocate for these types of experiences for their PTs, whether it be in a fieldwork classroom that does allow for rehearsals or a separate experience that has specific focus on these skills. Further, this study implies that PTs' mathematics teaching experiences should be focused on facilitating discussion and sense-making among students at the core.

Our findings also have implications for instructional mathematics coaches or other MTEs in leadership positions. We believe that coaching in-service teachers in a similar fashion, with a focus on building community among and between grade level teams to iterate on lessons in ways that promote sense-making can positively affect mathematics teaching in elementary classrooms. Providing spaces, where teachers can grapple with content and consider ways to elicit student thinking, is vital to developing these skills. This type of work is often expected to be carried out in classrooms with a cooperating teacher; however, we found that in this setting (with an MTE mentor instead of a traditional CT), PTs were able to be more flexible in their thinking about lesson design and more willing to take risks. The one-on-one setting allowed PTs to see in real time the effects of their instructional decisions. Indeed, this is a different skill than leading a whole class discussion, but does lay a foundation of practice that will serve them well in the classroom. As such, we argue that community-engaged opportunities such as CMP in combination with traditional fieldwork may better 
prepare PTs for teaching mathematics through problem-solving. Ultimately, providing in-depth, focused field experiences where PTs practice the skills that we want them to utilize in their mathematics classrooms has a lasting impact on their instruction.

Programs such as CMP capitalize on approximations of practice, funds of knowledge approaches, and sense-making to promote content and pedagogical growth among participants. Moreover, CMP serves the community and honors parents as educators. There is great potential in this type of program, and we believe it can transform mathematics education in our city and beyond.

Funding Project funded by the Department of Education Title V Funds (Award \# P031S180160, Northwest Vista Community College, lead institution).

\section{Declarations}

Ethics approval This manuscript is original and has not been partially of fully published elsewhere. All participants have signed a consent form and were informed of the study. This study has IRB approved from the university in where the study was conducted (ID\# i049360).

Informed consent Denisse M. Hinojosa, Ph.D., corresponding author, approves the participation and publication of the manuscript "The Community Mathematics Project: Using a Parent Tutoring Program to Develop Sense-Making Skills in Novice Mathematics Educators.” Emily P. Bonner, Ph.D., co-author, approves the participation and publication of this manuscript.

Conflict of interest The authors declare no competing interests.

\section{References}

Adams-Becker, S., Cummins, M., Davis, A., Freeman, A., Giesinger Hall, C., Ananthanarayanan, V., Langley, K., \& Wolfson, N. (2017). NMC Horizon Report: 2017 (Library). The New Media Consortium.

Aguirre, J., Mayfield-Ingram, K., \& Martin, D. B. (2013). The impact of identity in K-8 mathematics: Rethinking equity-based practices. National Council of Teachers of Mathematics.

AMTE Standards for Preparing Teachers of Mathematics. (2017). Chapter 2: Candidate knowledge, skills, and dispositions. Retrieved from https://amte.net/sptm/amte-standards-preparing-teachersmathematics/chapter-2-candidate-knowledge-skills-and

Arbaugh, F., Ball, D. L., Grossman, P., Heller, D. E., \& Monk, D. (2015). Dean's corner: Views on the state of teacher education in 2015. Journal of Teacher Education, 66, 435-445.

Bonner, E. P. \& Adams, T.L. (2012). Culturally responsive teaching in the context of mathematics: A grounded theory approach. Journal of Mathematics Teacher Education, 15(1), 25-38.

Hinojosa, D. M. (2018). Coaching during workshops and classroom observations: Promoting the appropriation of instructional strategies to teach emergent bilinguals. Individual paper presented at American Association of Colleges for Teacher Education (AACTE) 70th Annual Meeting, Baltimore, MD.

Ball, D. L., Thames, M. H., \& Phelps, G. (2008). Content knowledge for teaching: What makes it special? Journal of Teacher Education, 59(5), 389-407.

Beck, S. A., \& Huse, V. E. (2007). A virtual spin on the teaching of probability. Teaching Children Mathematics, 13(9), 482-486. https://doi.org/10.5951/TCM.13.9.0482

Berliner, D. (1985). Laboratory settings and the study of teacher education. Journal of Teacher Education, 36, 2-8. 
Braun, V., \& Clarke, V. (2006). Using thematic analysis in psychology. Qualitative Research in Psychology, 3(2), 77-101. https://doi.org/10.1191/1478088706qp063oa

Bruner, J. (1986). Actual minds, possible worlds. Harvard University Press.

Carpenter, T. P., Fennema, E., Franke, M. L., Levi, L., \& Empson, S. B. (1999). Children's mathematics: Cognitively guided instruction. Heinemann.

Carpenter, T. P., Franke, M. L., \& Levi, L. (2003). Thinking mathematically: Integrating arithmetic \& algebra in elementary school. Heinemann.

Civil, M., \& Andrade, R. (2002). Transitions between home and school mathematics: Rays of hope amidst the passing clouds. In G. de Abreu, A. J. Bishop, \& N. C. Presmeg (Eds.), Transitions between contexts of mathematical practices (pp. 149-169). Kluwer.

Civil, M., \& Bernier, E. (2006). Exploring images of parental participation in mathematics education: Challenges and possibilities. Mathematical Thinking and Learning, 8(3), 309-330. https://doi.org/ 10.1207/s15327833mt10803_6

Civil, M., Stoehr, K. J., \& Salazar, F. (2019). Learning with and from immigrant mothers: Implications for adult numeracy. Zdm, 52(3), 489-500. https://doi.org/10.1007/s11858-019-01076-2

Cochran-Smith, M., \& Villegas, A. M. (2015). Framing teacher preparation research: An overview of the field. Part i. Journal of Teacher Education, 66(1), 7-20.

Creswell, J. W. (2009). Research design: Qualitative, quantitative, and mixed methods approaches (3rd edition). Sage.

Darling-Hammond, L. (2006). Constructing 21st-century teacher education. Journal of Teacher Education, 57(3), 300-314.

Darling-Hammond, L. (2012). Creating a comprehensive system for evaluating and supporting effective teaching. Stanford, CA: Stanford Center for Opportunity Policy in Education.

Darling-Hammond, L., Chung, R., \& Frelow, F. (2002). Variation in teacher preparation: How well do different pathways prepare teachers to teach? Journal of Teacher Education, 53(4), 286-302.

Dewey, J. (1904/1965). The relation of theory to practice in the education. In McMurray, C. (Ed.), The third yearbook of the National Society for the Scientific Study of Education, part I (pp. 9-30). Chicago, IL: University of Chicago Press.

Diez, M. E. (2010). It is complicated: Unpacking the flow of teacher education's impact on student learning. Journal of Teacher Education, 61, 441-450.

Diaz-Palomar, J., Menendez, J. M., \& Civil, M. (2011). Learning mathematics with adult learners: Drawing from parents' perspectives. Revista Latinoamericana De Investigacion En Matematica Educativa, 14(1), 71-94.

Ericsson, A. (2002). Attaining excellence through deliberate practice: Insights from the study of expert performance. In Ferrari, M. (ed.) The educational psychology series. The pursuit of excellence through education (pp. 21-55). Lawrence Erlbaum Associates Publishers.

Flecha, R. (2000). Sharing words: Theory and practice of dialogic learning. Lanham, M. D: Rowman \& Littlefield. In Diaz-Palomar, J., Menendez, J.M., \& Civil, M. (2011). Learning mathematics with adult learners: Drawing from parents' perspectives. Revista Latinoamericana de Investigacion en Matematica Educativa, 14(1), 71-94.

Fraser, J. W. (2007). Preparing America's teachers: A history. Teacher College Press.

Ginsburg, H. P. (2006). Mathematical play and playful mathematics: A guide for early education. In D. Singer, R. M. Golinkoff, \& K. Hirsh-Pasek (Eds.), Play = learning: How play motivates and enhances children's cognitive and social-emotional growth (pp. 145-165). Oxford University Press.

Grossman, P. (2005). Pedagogical approaches in teacher education. In M. Cochran-Smith \& K. Zeichner (Eds.), Studying teacher education (pp. 425-476). Routledge.

Grossman, P., Hammerness, K., \& McDonald, M. (2009). Redefining teaching, re-imagining teacher education. Teachers and Teaching, Theory and Practice, 15(2), 273-289. https://doi.org/10.1080/ 13540600902875340

Gutiérrez, M. (2018). Estilos de aprendizaje, estrategias para enseñar. Su relación con el desarrollo emocional y "aprender a aprender." Tendencias Pedagógicas, 31, 83-96.

Hammer, D., \& van Zee, E. (2006). The beginnings of scientific reasoning. Seeing the science in children's thinking: Case studies of student inquiry in physical science (pp. 13-35). Heinemann.

Henry, G. T., Campbell, S. L., Thompson, C. L., Patriarca, L. A., Luterbach, K. J., Lys, D. B., \& Covington, V. M. (2013). The predictive validity of measures of teacher candidate programs and performance: Toward an evidence-based approach to teacher preparation. Journal of Teacher Education, 64, 439-453. 
International Society for Technology in Education (ISTE). (2000). National educational technology standards for students: Connecting curriculum and technology. Eugene, Author.

Jimenez-Castellanos, O., Ochoa, A. M., \& Olivos, E. M. (2016). Operationalizing transformative parent engagement in Latino school communities: A case study. Journal of Latino/Latin American Studies, $8(1), 93-107$.

Kaufman, K. (2015). Information communication technology: Challenges \& some prospects from preservice education to the classroom. Mid-Atlantic Education Review, 2, 1-11.

Kerrigan, J. (2002). Powerful software to enhance the elementary school mathematics program. Teaching Children Mathematics, 8(6), 364-377.

Knijnik, G. (2003). Currículo, etnomatemática e educação popular: Um estudo em um assentamento do Movimento Sem-Terra. Reflexão e Ação, 10(1), 47-64.

Lapadat, J. C. (2010). Thematic analysis. In Mills, A.J., Durepose, G. \& Wiebe, E. (Eds.), Encyclopedia of Case Study Research (Vol. 2, pp. 925-927). SAGE publications Inc.

Leedy, P. O., \& Ormrod, J. E. (2013). Practical research: Planning and design (10th edition). Pearson.

Leont'ev, A. N. (1981). Problems of the development of the mind. Progress.

Little, J. W. (1990). The persistence of privacy: Autonomy and initiative in teachers' professional relations. Teachers College Record, 91(4), 509-536.

Lortie, D. C. (1975). Schoolteacher: A sociological study. University of Chicago.

Mistretta, R. (2005). Integrating technology into the mathematics classroom: The role of the teacher preparation programs. The Mathematics Educator, 15(1), 18-24.

Moll, L., Amanti, C., Neff, D., \& González, N. (1992). Funds of knowledge for teaching: Using a qualitative approach to connect homes and classrooms. Theory into Practice, 31, 132-141. https://doi.org/ $10.1080 / 00405849209543534$

Moll, L., \& Greenberg, J. M. (1990). Creating zones of possibilities: Combining social constructs for instruction. In Moll, L.C. (ed.) Vygotsky and education: Instructional implications and applications of sociohistorical psychology. New York, NY: Cambridge University Press.

Moyer-Packenham, P. S., \& Suh, J. M. (2012). Learning mathematics with technology: The influence of virtual manipulatives on different achievement groups. Journal of Computers in Mathematics and Science Teaching, 31(1), 39-59.

Moyer-Packenham, P. S., \& Westenskow, A. (2013). Effects of virtual manipulatives on student achievement and mathematics learning. International Journal of Virtual and Personal Learning Environments, 4(3), 35-50. https://doi.org/10.4018/jvple.2013070103

Muir, T. (2011). Join the club: Engaging parents in mathematics education. In J. Clark, B. Kissane, J. Mousley, T. Spencer, \& S. Thornton (Eds.), Mathematics: Traditions and [new] practices (Proceedings of the 2011 AAMT-MERGA Conference, pp. 531-539). Alice Springs, NT: MERGA.

Muir, T. (2012). Its in the bag: Parental involvement in a numeracy at-home program. Australasian Journal of Early Childhood, 37(2), 27-33.

National Council of Teachers of Mathematics (NCTM). (2000). Principles and standards for school mathematics. Reston, VA: National Council of Teachers of Mathematics.

National Council of Supervisors of Mathematics (NCTM). (2013). "Improving student achievement in mathematics by using manipulatives with classroom instruction" 11 . https://www.movingwithmath.com/ncsmposition-paper/2/\#zoom=z

Odden, T. O. B., \& Russ, R. S. (2017). Defining sensemaking: Bringing clarity to the fragmented theoretical construct. Science Education, 103(1), 187-205. https://doi.org/10.1002/sce.21452

Pendleton, D., Schofield, T., Tate, P., \& Havelock, P. (2003). The new consultation: Developing doctorpatient communication. Oxford University Press. https://doi.org/10.1111/j.1369-7625.2003.00263.x

Plaza, P., González, M. J., Montero, B., \& Rubio, C. (2004). Matemáticas críticas y transformadoras en la educación de personas adultas [Critical and transforming mathematics in adult education]. Málaga, Spain: Ediciones Aljibe

Quintos, B., Civil, M., \& Bratton, J. (2019). Promoting change through a formative intervention: Contradictions in mathematics education parental engagement. Mind, Culture, and Activity., 26(2), 171186. https://doi.org/10.1080/10749039.2019.1602656

Remillard, J. T., \& Jackson, K. (2006). Old math, new math: Parents' experiences with standardsbased reform. Mathematical Thinking and Learning, 8(3), 231-259. https://doi.org/10.1207/ s15327833mt10803_3

Rogoff, B. (1990). Apprenticeship in thinking. Oxford University Press.

Shulman, L. S. (1998). Theory, practice, and the education of professionals. Elementary School Journal, 98(5), 511-526. https://doi.org/10.1086/461912 
Stein, M. K., Engle, R. A., Smith, M. S., \& Hughes, E. K. (2008). Orchestrating productive mathematical discussions: Five practices for helping teachers move beyond show and tell. Mathematical Thinking and Learning, 10(4), 313-340. https://doi.org/10.1080/10986060802229675

Stone, C. N. (1993). Urban regimes and the capacity to govern: A political economy approach. Journal of Urban Affairs, 15(1), 1-28. https://doi.org/10.1111/j.1467-9906.1993.tb00300.x

Swars, S., \& Hart, L. C. (2009). A longitudinal study of a developmental teacher preparation program on elementary prospective teachers' mathematics beliefs. Journal of Mathematics Teacher Education, 12(2009), 47-66. https://doi.org/10.1007/s10857-008-9092-x

Vygotsky, L. S. (1978). Interaction between learning and development. In M. Gauvain \& M. Cole (Eds.), Readings on the development of children (4th ed., pp. 34-42). Worth Publishers.

Vygotsky, L. S. (1987). Thinking and speech (N. Minick, Trans.). In R. W. Rieber, \& A. S. Carton (Eds.), The collected works of L. S. Vygotsky. Volume 1: Problems of general psychology (pp. 39-285). New York, NY: Plenum Press.

Wenger, E. (1998). Communities of practice: Learning as a social system. Systems Thinker, 9(5), 1-8.

Wilson, S. M., Floden, R. E., \& Ferrini-Mundy, J. (2001). Teacher preparation research: Current knowledge, gaps, and recommendations. Center for the Study of Teaching and Policy. Retrieved from: https://www.education.uw.edu/ctp/content/teacher-preparation-research-current-knowledge-gapsand-recommendations on 2 Aug 2021.

Wright, R. T. (1999). Technology education: Essential for a balanced education. NASSP Bulletin, 83(60), $16-22$.

Yin, R. K. (2014). Case study research: Design and methods (5th edition). SAGE Publications.

Zbiek, R. M., Heid, M. K., Blume, G. W., \& Dick, T. P. (2007). Research on technology in mathematics education: The perspective of constructs. In F. K. Lester (Ed.), Second handbook of research on mathematics teaching and learning (Vol. 2, pp. 1169-1207). Information Age Publishing Inc.

Zeichner, K. (2010). Rethinking the connections between campus courses and field experiences in college and university-based teacher education. Journal of Teacher Education, 89(11), 89-99. https://doi. org/10.1177/0022487109347671

Publisher's Note Springer Nature remains neutral with regard to jurisdictional claims in published maps and institutional affiliations.

\section{Authors and Affiliations}

\section{Denisse M. Hinojosa ${ }^{1}\left[\right.$ - Emily P. Bonner ${ }^{1}(\mathbb{C}$}

Emily P. Bonner

emily.bonner@utsa.edu

1 University of Texas at San Antonio, San Antonio, TX, USA 